ЗАХАРОВ Виктор Михайлович - доктор социологических наук, директор Института экономики и управления Белгородского государственного национального исследовательского университета (308015, Россия, г. Белгород, ул. Победы, 85)

КОМКОВ Константин Анатольевич - соискатель кафедры социальных технологий и государственной службы Белгородского государственного национального исследовательского университета (308015, Россия, г. Белгород, ул. Победы, 85)

ПАСТЮК Марина Викторовна - соискатель кафедры социальных технологий и государственной службы Белгородского государственного национального исследовательского университета (308015, Россия, г. Белгород, ул. Победы, 85)

САПРЫКА Василий Александрович - аспирант кафедры социологии и управления Белгородского государственного технологического университета им. В.Г. Шухова (308012, Россия, г. Белгород, ул. Костюкова, 46; sapryka@icbci.info)

\title{
ОТНОШЕНИЕ НАСЕЛЕНИЯ К ЦИФРОВЫМ ТЕХНОЛОГИЯМ ОБЩЕСТВЕННО-ПОЛИТИЧЕСКОГО УЧАСТИЯ И ВЗАИМОДЕЙСТВИЯ С ВЛАСТЬЮ
}

\begin{abstract}
Аннотация. В статье рассматриваются вопросы применения цифровых технологий в рамках общественно-политического участия и коммуникации общества с властью. Приводятся данные авторского социологического исследования, включающего массовый анкетный опрос населения Белгородской обл. ( $N=500)$. На основе анализа эмпирических данных авторы делают вывод, что в настоящее время российское общество признает практики применения цифровых технологий в общественно-политическом участии и коммуникации с властью лишь на уровне конвенционального согласия.
\end{abstract}

Ключевые слова: публичная власть, общественно-политическое участие, цифровизация, общественный договор

Введение. В последние годы цифровизация все плотнее вплетается в ткань современного общества, становясь частью множества форм человеческих отношений. Практически все элементы общественной системы в той или иной степени преобразуются под все более растущим влиянием цифровых технологий.

На данном этапе цифровизация представлена скорее набором стихийных поведенческих практик, которые еще не в полной мере институционализированы, а отношение к ним населения еще окончательно не сформировалось. В этих условиях большое значение приобретает исследование цифровизации как всеобъемлющего и общемирового процесса, изучение ее влияния на современное общество, отслеживание рисков и угроз, разработка мер по противодействию им.

Однако остается не изученным реальное отношение населения к цифровым практикам общественно-политического участия и коммуникации с властью. Неизвестно, считает ли общество цифровую коммуникацию легитимной и доверяет ли современным технологиям в вопросах политического выбора. Уже в настоящее время требуются комплексные социологические исследования по проблематике цифровизации системы публичного управления и использования цифровых практик в общественно-политической сфере. Без должного научного обоснования цифровизация может окончательно сформироваться как стихийный и неуправляемый процесс, со всеми присущими ему рисками и многочисленными угрозами. 
Методика и методология. Принимая во внимание концепцию П. Хоровица, согласно которой цифровизация представляет собой процесс переноса данных в цифровую дискретную (электронную) форму, в рамках настоящего исследования мы используем более широкое понимание данного термина [Хоровиц, Хилл 1993]. Ключевым аспектом в данном случае является социальный характер данного феномена, который подчеркивается, например, в работах Харрингтона, приписывающего цифровизации постепенный перенос различных сфер общественных отношений в цифровую форму [Harrington 1989].

По нашему мнению, цифровизация представляет собой процесс всемирной социальной, экономической, политической и культурной интеграции общества в цифровое пространство, когда цифровые практики становятся общеупотребительными, а наличие минимальных навыков использования цифровых технологий - необходимым для сохранения диспозиций в социальной структуре современного общества.

В этой связи большое значение для настоящего исследования имеет также концепция цифрового разрыва, определяющая, что распространение цифровых технологий обусловливает как увеличение существующих социальных неравенств, так и возникновение новых [Castells 2012; Кастельс, Химманен 2002: 15].

Эмпирической основой исследования послужили результаты авторского социологического опроса «Модификация социального неравенства в условиях дигитализации российского общества», организованного в январефеврале 2020 г. Исследование включало массовый анкетный опрос населения Белгородской обл. $(N=500)$. Использовалась квотная половозрастная выборка, погрешность составила не более $2,5 \%$.

Результаты исследования. Одной из ключевых целей исследования являлось определение активности использования населением цифровых практик при общественно-политическом участии. Роль цифровых технологий и сети Интернет в политическом процессе только возрастает [Шилов 2018: 30]. Помимо уже легитимного и формально закрепленного дистанционного электронного голосования ${ }^{1}$, активно развиваются стихийные неинституционализированные цифровые практики общественно-политического участия: интернет-митинги, форумы, чаты и онлайн-каналы с обсуждением актуальной политической информации и координацией протестных акций, интернетпетиции и др.

Вместе с тем, как показали результаты исследования, цифровые технологии и Интернет для общественно-политического участия в жизни страны используют всего $15,4 \%$ респондентов. Более чем $2 / 3$ опрошенных $(69,8 \%)$ цифровые технологии для этих целей не используют (см. табл. 1).

Цифровые технологии и сеть Интернет, по мнению респондентов, обусловили увеличение возможностей для участия в общественно-политической жизни страны. Так, 49\% опрошенных считают, что активное развитие цифровых технологий в той или иной степени увеличило возможности. $26,2 \%$ считают, что верно нечто среднее. И лишь $24,8 \%$ считают, что возможности, наоборот, уменьшились (см. табл. 2.).

Учитывая взаимосвязь ответов на два предыдущих вопроса, можно предположить, что существенная часть населения осведомлены о существовании цифровых практик общественно-политического участия, но пока их использует лишь малая часть населения.

1 Дистанционное электронное голосование. - ЦИК. Доступ: http://www.cikrf.ru/ analog/constitution-voting/participants/distantsionnoe-elektronnoe-golosovanie/ (проверено 19.03.2021). 
Таблииа 1

Распределение ответов на вопрос: «Используете ли Вы цифровые технологии и Интернет для общественно-политического участия в жизни страны?»

\begin{tabular}{|c|l|c|c|}
\hline № & \multicolumn{1}{|c|}{ Вариант ответа } & Чел. & $\%$ \\
\hline 1 & Да & 77 & 15,40 \\
\hline 2 & Нет & 349 & 69,80 \\
\hline 3 & Затрудняюсь ответить & 74 & 14,80 \\
\hline & Итого & 500 & 100,00 \\
\hline
\end{tabular}

Таблица 2

Распределение ответов на вопрос: «Как Вы считаете, обусловило ли активное развитие цифровых технологий увеличение возможностей для общественнополитического участия в жизни страны?»

\begin{tabular}{|c|l|c|c|}
\hline № & \multicolumn{1}{|c|}{ Вариант ответа } & Чел. & \% \\
\hline 1 & Однозначно да & 41 & 8,20 \\
\hline 2 & Скорее да, чем нет & 204 & 40,80 \\
\hline 3 & Верно нечто среднее & 131 & 26,20 \\
\hline 4 & Скорее нет, чем да & 43 & 8,60 \\
\hline 5 & Однозначно нет & 81 & 16,20 \\
\hline 6 & Затрудняюсь ответить & 0 & 0,00 \\
\hline & Итого & 500 & 100,00 \\
\hline
\end{tabular}

Аналогичная ситуации складывается в отношении населения к цифровым технологиям коммуникации с органами власти. Считают, что на доступ человека к власти оказывает влияние его уровень владения цифровыми технологиями $44,8 \%$ респондентов, а $20,4 \%$ с этим в той или иной степени не согласны (см. табл. 3).

Таблица 3

Распределение ответов на вопрос: «Считаете ли Вы, что на доступ человека к власти оказывает влияние уровень его навыков и возможностей использования электронных устройств и цифровых технологий?»

\begin{tabular}{|c|l|c|c|}
\hline № & \multicolumn{1}{|c|}{ Вариант ответа } & Чел. & $\%$ \\
\hline 1 & Однозначно да & 52 & 10,40 \\
\hline 2 & Скорее да, чем нет & 172 & 34,40 \\
\hline 3 & Верно нечто среднее & 94 & 18,80 \\
\hline 4 & Скорее нет, чем да & 71 & 14,20 \\
\hline 5 & Однозначно нет & 31 & 6,20 \\
\hline 6 & Затрудняюсь ответить & 80 & 16,00 \\
\hline & Итого & 500 & 100,00 \\
\hline
\end{tabular}

Тем не менее респонденты считают, что коммуникация с властью посредством цифровых технологий имеет определенные преимущества. 30,2\% отме- 
тили, что власть в случае электронной коммуникации быстрее реагирует на обращения; 22,2\% подчеркнули, что цифровая коммуникация проще в сравнении с традиционными формами; а 19,2\% считают, что в случае электронного взаимодействия они получают более доступную форму ответа (см. табл. 4.).

Таблица 4

Распределение ответов на вопрос: «Какие преимущества имеет коммуникация с властью посредством цифровых технологий перед традиционными формами?»

\begin{tabular}{|c|l|c|c|}
\hline № & \multicolumn{1}{|c|}{ Вариант ответа } & Чел. & \% \\
\hline 1 & $\begin{array}{l}\text { Проще в сравнении с традиционными } \\
\text { формами коммуникации }\end{array}$ & 111 & 22,20 \\
\hline 2 & Власть быстрее реагирует & 151 & 30,20 \\
\hline 3 & Более высокая эффективность & 51 & 10,20 \\
\hline 4 & Более доступная форма ответа & 96 & 19,20 \\
\hline 5 & Другое & 0 & 0,00 \\
\hline 6 & Затрудняюсь ответить & 91 & 18,20 \\
\hline & Итого & 500 & 100,00 \\
\hline
\end{tabular}

Таким образом, результаты исследования еще раз подтверждают возрастание роли цифровых технологий в общественно-политическом участии и коммуникации с властью. У большей части населения, безусловно, сформировалось представление, что коммуникация такого рода является возможной, хотя и лишь малая доля респондентов используют такие практики в повседневности.

В данном случае важным вопросом является уровень доверия цифровых технологиям и их применению в таких важных сферах человеческих отношений. Пока данные практики носят разобщенный и стихийный характер, отсутствуют четко сформулированные и закрепленные социальные нормы их применения, население склоняется скорее к традиционным формам взаимодействия.

Обращаясь к феномену цифрового неравенства, когда часть населения не обладает необходимыми навыками или возможностями применения цифровых технологий и извлечения преимуществ из их использования, стоит отметить, что существенная доля респондентов еще не сформировали объективные представления о новых критериях дифференциации общества.

Так, например, респондентам был задан вопрос касательно того, считают ли они справедливыми и/или законными некоторые следствия владения цифровыми технологиями, в частности неравенство в отношении общественнополитического участия и доступа к власти.

Лишь 23,4\% считают возникшее неравенство в отношении общественнополитического участия законным, а 27,2\% - справедливым. Неравенство в отношении доступа к власти оценивают немногим лучше. Так, $30,4 \%$ респондентов считают его законным, и лишь $25,2 \%$ - справедливым. При этом в обоих случаях около $60 \%$ опрошенных не смогли дать однозначные ответы на данные вопросы.

Результаты социологического исследования позволяют сделать вывод, что население уже признало цифровые технологии в общественно-политическом участии и доступе к власти, а также присущие им неравенства на уровне конвенционального согласия. Но лишь малая часть признает их легитимными и справедливыми. Причиной тому может являться низкий уровень институционализации цифрового взаимодействия, разрозненное применение цифровых практик, отсутствие соответствующих норм и правил. 
Обсуждение результатов. Дальнейшее внедрение цифровых технологий в процессы общественно-политического участия и коммуникации с властью должно сопровождаться переходом от конвенционального признания самого существования таких практик к их постепенной легитимации и институционализации.

Однако попытки государственного регулирования данной сферы сталкиваются с рядом проблем. Во-первых, деятельность власти зачастую не отвечает требованиям современного динамично развивающегося цифрового общества: бюрократизированность и формализованность государственных мер обусловливают их неэффективность и несвоевременность. Во-вторых, слабое понимание принципов функционирования цифрового пространства и высокий уровень самоорганизованности сетевого сообщества приводят к тому, что ответной реакцией на меры государственного регулирования является усложнение цифровых практик в обход создаваемых ограничений.

Дискуссии о свободе, доминировании и вмешательстве сопровождаются надеждой на бесконфликтную стратегию взаимодействия цифрового управления и отношений между гражданами, базирующуюся на сотрудничестве, прозрачности и честности, которые основаны на алгоритмах цифровых технологий. Многие убеждены, что алгоритмическое управление устранит опасность неэффективности и недоверия, возложив часть ответственности на безличные процедуры [Сморгунов 2019: 63].

В данном случае представляется целесообразным обратиться к концепции общественного договора, которая, зародившись еще в XVII в., в современных условиях была существенно доработана [Ролз 2010; Southwood 2010; Хабермас 2001]. По мнению современных авторов, «общественный договор определяет базовые границы и характеристики социального действия и фундаментальные принципы согласования противоречивых, конфликтных интересов» [Кузьмин 2014: 94].

Модификация существующего общественного договора между уже цифровым обществом и публичной властью или инициация процесса принятия нового позволит закрепить четкие рамки и нормы применения цифровых практик, определить границы дозволенного и, наконец, повысить эффективность системы государственного управления путем раскрытия потенциала цифровизации.

Это позволит избежать множественных рисков и угроз стихийной цифровизации, когда, например, часть населения будет лишена преимуществ электронного взаимодействия ввиду отсутствия доверия к нелегитимным цифровым практикам общественно-политического участия и коммуникации с властью. При этом стохастичность и непредсказуемость цифровизации позволяет говорить о возможности будущих, но еще не проявившихся угроз, тогда как модифицированный общественный договор может стать одним из способов предупреждения возможных рисков.

Заключение. Публичная власть не в праве игнорировать скоротечные и всеобъемлющие процессы цифровизации общества, которые постепенно становятся неотъемлемой частью практически всех социальных институтов. Тотальная формализация процесса цифровой коммуникации между органами власти и населением уже демонстрирует свою неэффективность ввиду бюрократизации процесса определения и закрепления норм, с одной стороны, и стихийностью самой цифровизации - с другой.

В этой связи необходимо обратиться к более масштабным социальным концепциям, одной из которых может стать теория общественного договора, который в условиях формирования цифрового общества критически нуждается в 
обновлении и актуализации. Необходимо определить границы и правила взаимодействия между цифровым обществом и публичной властью, закрепить ценностные ориентиры и легитимировать новые формы коммуникации.

Исследование выполнено при финансовой поддержке РФФИ и ЭИСИ в рамках научного проекта № 20-011-31535.

\section{Список литературы}

Кастельс М., Химманен П. 2002. Информационное общество и государство благосостояния: финская модель. М.: Логос. 224 с.

Кузьмин Г.С. 2014. Общественный договор как фундаментальный политический механизм регулирования конфликтов. - Власть. № 7. С. 92-96.

Ролз Д. 2010. Теория справедливости. М.: URSS. 534 с.

Сморгунов Л.В. 2019. Институционализация управляемости и проблема контроля в пространстве цифровых коммуникаций. - Южно-Российский жсунал социальных наук. № 3. С. 62-75.

Хабермас Ю. 2001. Вовлечение другого. Очерки политической теории. СПб: Наука. 417 с.

Хоровиц П., Хилл У. 1993. Искусство схемотехники: в 3 т. М.: Мир. Т. 2. 371 с.

Шилов В.В. 2018. Роль Интернета в политической сфере социума. Часть 1. Власть. Т. 26. № 9. С. 29-34.

Castells M. 2012. Networks of Outrage and Hope. Social Movements in the Internet Age. Massachusetts: Polity Press. 200 p.

Harrington J.G. 1989. School/University/Business Partnership: Collaboration in a Tripartite Partnership: PhD thesis. N.Y. 139 p.

Southwood N. 2010. Contractualism and the Foundations of Morality. Oxford: Oxford University Press. 216 p.

ZAKHAROV Viktor Mikhailovich, Dr.Sci. (Soc.), Director of the Institute of Economics and Management, Belgorod National Research University (85 Pobedy St, Belgorod, Russia, 308015)

KOMKOV Konstantin Anatol'evich, external doctorate student of the Chair of Social Technologies and Public Service, Belgorod National Research University (85 Pobedy St, Belgorod, Russia, 308015)

PASTJUK Marina Viktorovna, external doctorate student of the Department of Social Technologies and Public Service, Belgorod National Research University (85 Pobedy St, Belgorod, Russia, 308015)

SAPRYKA Vasiliy Aleksandrovich, postgraduate student of the Chair of Sociology and Management, Shukhov Belgorod State Technological University (46 Kostyukova St, Belgorod, Russia, 308012; sapryka@icbci.info)

\section{THE ATTITUDE OF THE POPULATION TO DIGITAL TECHNOLOGIES OF PUBLIC AND POLITICAL PARTICIPATION AND INTERACTION WITH THE AUTHORITIES}

Abstract. The article examines the issues of using digital technologies in the framework of social and political participation and communication between society and the authorities, as well as the attitude of the population to these practices. The data of the authors' sociological research, including a mass questionnaire survey of the population of the Belgorod Region $(N=500)$, carried out using a quota age and sex sample, are presented. Based on the analysis of empirical data, the authors conclude that at present the Russian society recognizes the practice of using digital technologies in public and political participation and communication with the authorities only at the level of conventional consent. The reason for this may be the low level of institutionalization of digital interaction, the scattered use of digital practices, and the absence of relevant 
rules and regulations. At the same time, digitalization, being a spontaneous and poorly controlled process, carries multiple risks and threats to Russian society. However, the implementation of active measures to legitimize and institutionalize digitalization processes faces a number of problems, from excessive bureaucracy of government instruments to opposition from the network community. The solution to this problem can be the adoption of a new or modification of the existing social contract between public authorities and digital society. This will allow us to consolidate clear frameworks and norms for the use of digital practices, determine the boundaries of what is permissible and, finally, increase the efficiency of the public administration system by unlocking the potential of digitalization. At the same time, the stochasticity and unpredictability of digitalization makes it possible to assert about future, but not manifested yet threats, while a modified social contract can become one of the ways to prevent possible risks.

Keywords: public administration, social and political participation, digitalization, social contract

ВОЕВОДИНА Екатерина Владимировна - кандидат социологических наук, доцент; доцент департамента социологии Финансового университета при Правительстве РФ (125993, Россия, г. Москва, ГСП-3, Ленинградский пр-кт, 49; ekaterinavoevodina@yandex.ru)

\section{РОЛЬ АКАДЕМИЧЕСКОГО ИНБРИДИНГА В РЕАЛИЗАЦИИ НАУЧНО- ИССЛЕДОВАТЕЛЬСКОГО ПОТЕНЦИАЛА СТУДЕНТОВ ИЗ СОЦИАЛЬНО УЯЗВИМЫХ СЛОЕВ НАСЕЛЕНИЯ}

Аннотация. В статье раскрываются особенности академического инбридинга, его виды и риски, выявленные российскими и зарубежными исследователями. Предпринята попытка анализа инбридинга с точки зрения реализации «третьей миссии» университетов, в рамках которой предполагается содействие развитию потенциала студентов из социально уязвимых групп населения (прежде всего, имеющих инвалидность, малоимущих). Автор обосновывает принципы модели «здорового» инбридинга, снижающей риски возникновения отрицательных эффектов.

Ключевые слова: академический инбридинг, «третья миссия» университетов, научно-исследовательский потенциал, студент, инвалидность, социально уязвимые группы населения

Q овременное общество подвергается ряду изменений в силу ускорения темпов научно-технологического развития, что сопровождается бурным ростом производства и потребностей населения. Происходит переход к цифровой экономике, влекущей за собой ряд кардинальных изменений в различных областях жизнедеятельности. Все это обостряет вопросы подготовки квалифицированных кадров и неизбежно влечет за собой качественные изменения в вузовской сфере. Задача развития научно-исследовательского потенциала молодежи, выявления и взращивания талантов становится приоритетной целью, обеспечивающей конкурентоспособность эффективной образовательной системы. Руководство университетов заинтересовано в привлечении квалифицированных научно-педагогических кадров, образующих интеллектуальный потенциал вуза, от которого зависит его эффективность и жизнеспособность. Сравнительные исследования образовательных систем Китая, Индии, Бразилии и России показывают, что страны, активно инвестирующие в развитие научно-исследовательского потенциала обучающихся и препода- 